\title{
Effect of palladium on the microstructure and grain boundary complexions in SiC
}

\author{
David J. Navarro-Solís, Félix Cancino-Trejo, Eddie López-Honorato* \\ Centro de Investigación y de Estudios Avanzados del IPN (CINVESTAV), Unidad \\ Saltillo, Av. Industria Metalúrgica 1062, Ramos Arizpe, 25900, México. \\ ${ }^{*}$ Corresponding author's e-mail: eddie.lopez@cinvestav.edu.mx
}

\section{Abstract}

One of the main challenges in the study of TRISO (Tristructural Isotropic) coated fuel particles is the understanding of the diffusion of fission products through SiC. Among the elements produced inside the uranium kernel, it has been suggested that $\mathrm{Pd}$ might enhance the diffusion of other fission products. In this work we have studied the interaction between $\mathrm{Pd}$ and $\mathrm{SiC}$. We have observed that as $\mathrm{Pd}$ diffuses it can change the chemical composition and microstructure of SiC. Electron Backscattered Diffraction (EBSD) analysis showed that Pd increased the amount of high angle grain boundaries from 47 to $59 \%$. Furthermore, we have observed that as Pd diffused, it changed the composition of $\mathrm{SiC}$ by leaving a trail of excess carbon at the grain boundary. This change in localized chemical composition and microstructure suggests a grain boundary complexion transition induced by $\mathrm{Pd}$ and a new way in which Pd can lead to faster diffusion routes for other fission products. 


\section{Introduction}

The TRISO (Tristructural Isotropic) coated fuel particle consists of a kernel (uranium oxide or oxycarbide) of 300-500 $\mu \mathrm{m}$ in diameter coated with three layers of pyrolytic carbon (PyC) and one of silicon carbide ( $\mathrm{SiC})$. The purpose of these coatings is to work as a miniature fission product containment vessel, capable of retaining within the particle all relevant fission products. Among these coatings, SiC is considered the most important as it retains most of the metallic fission products and provides the mechanical strength to the particle. $\cdot^{1-3}$

Among all the fission products generated in the kernel, Pd has received particular attention as it is capable of chemically interacting with SiC producing palladium silicides $\left(\mathrm{Pd}_{2} \mathrm{Si}\right.$ at temperatures between 1000 and $\left.1300{ }^{\circ} \mathrm{C}\right)$ and carbon..$^{4-6}$ Furthermore, it has been suggested that $\mathrm{Pd}$ can enhance the diffusion of other relevant fission products such as $\mathrm{Ag}^{110 m}$ (a strong $\gamma$-ray emitter), however, it is still unclear how Pd could enhance such diffusion since the original theory suggesting the formation of a solid solution has not been corroborated experimentally, since Pd and Ag have been observed to diffuse separately. ${ }^{7-10}$

Recently, Cancino et al. identified three types of Dillon-Harmer grain boundary complexions ${ }^{11}$ in $\mathrm{SiC}$ and suggested that the complex diffusion behavior of fission products could be explained through the existence of grain boundary complexions and complexion transitions. ${ }^{12}$ Therefore, in this work, we studied the effect of $\mathrm{Pd}$ on the microstructure of $\mathrm{SiC}$. We observed for the first time that Pd can induce important changes in composition in $\mathrm{SiC}$ at the grain boundaries. This change in composition 
could be responsible for some previous results found in the literature suggesting that Pd can enhance the diffusion of $\mathrm{Ag}$.

\section{Experimental procedure}

A SiC wafer produced by chemical vapor deposition (provided by Dow Chemicals, no information of the deposition conditions were provided) was used. Small rectangular pieces of $\mathrm{SiC} \sim 3 \times 2 \mathrm{~mm}$ were placed in contact with Pd powder (Sigma Aldrich, $\geq 99.9 \%$ purity, particle size $<1 \mu \mathrm{m}$ ) at $1300^{\circ} \mathrm{C}$ for 3 hours under argon atmosphere. After heat treatment, the samples were embedded in copper loaded resin and polished up to its cross-section using SiC grinding paper, diamond paste and colloidal silica.

The microstructure was characterized using a scanning electron microscope (Philips XL30-ESEM) and energy dispersive X-ray spectroscopy (EDS). Electron backscattered diffraction (EBSD) was performed using orientation imaging microscopy (OIM) and the TSL-OIM 3.5 program with $20 \mathrm{kV}$ of accelerating voltage, $15 \mathrm{~mm}$ working distance, a $70^{\circ}$ tilt and a step size of $0.8 \mathrm{~mm}$; measuring more than 50 distinctive grains for better accuracy. Grain size was measured according to the ASTM-E112-12 standard, whereas a minimum adjacent misorientation of $<5^{\circ}$ was defined for the identification of grain boundaries, affecting approximately $10 \%$ of the data. ${ }^{13}$ Samples for transmission electron microscopy (TEM) were obtained using focused ion beam milling (FEI-Scios dual-beam). TEM was performed using an FEI- 
Talos F200X with four in-column Super-X EDS detectors with a beam current of 300 $\mathrm{pA}$ and a collection time of $10 \mathrm{~min}$.

\section{Results and Discussion}

Figure 1 shows that after heat treatment at $1300^{\circ} \mathrm{C}, \mathrm{Pd}$ was found well within SiC. An EBSD map was taken in an area where Pd already diffused in order to identify possible changes introduced by Pd. Figure $1 \mathrm{~b}$ shows the inverse pole figure (IPF) and the standard stereographic triangle (SST), in which a mixture of equiaxed and columnar grains with no preferred orientation can be seen. This random orientation before and after Pd interaction was also corroborated by pole figures in Fig. S1. The grain boundary character distribution before and after heat treatment is shown in Figure 2. It can be seen that as-produced SiC grain boundaries were dominated by high angle $\left(>15^{\circ}, 47 \%\right)$ and Coincidence Site Lattice (CSL) boundaries (36\%), with low angle grain boundaries $\left(<15^{\circ}\right)$ accounting for only $17 \%$. However, after heat treatment with $\mathrm{Pd}$, this distribution changed to $59 \%$ high angle grain boundaries, $24 \%$ CSL and $17 \%$ low angle grain boundaries; $12 \%$ more high angle grain boundaries than the as-produced material. This change in microstructure was reflected on the average grain size detected as it changed from 10 to $17 \mu \mathrm{m}$ after heat treatment.

Furthermore, when element maps where taken on the areas where Pd was present, it was possible to identify $\mathrm{Pd}, \mathrm{Si}$, and $\mathrm{C}$ (Fig. S2). High concentrations of carbon were observed alongside Pd, showing a deficiency of Si in the same areas (Figs. S2 b-d). 
This variation in $\mathrm{C}$ and $\mathrm{Si}$ concentration due to the presence of $\mathrm{Pd}$ was corroborated by TEM. Fig. 3 shows the presence of a Pd cluster of approximately $60 \mathrm{~nm}$ in length as it diffused through $\mathrm{SiC}$. Element maps show that as the $\mathrm{Pd}$ particle traveled through $\mathrm{SiC}$, it left behind an area with silicon deficiency and excess carbon. This change in composition could be due to the chemical reaction between $\mathrm{SiC}$ and $\mathrm{Pd}$ producing palladium silicides and carbon. ${ }^{5,14}$ This change in composition could be described as a grain boundary complexion transition towards the formation of a nanolayer. The formation of such a layer could also be seen in Fig. S3, where the formation of a nanolayer with a higher concentration of $\mathrm{C}$ compared to bulk $\mathrm{SiC}$ was also identified (Table S1) between two triple points containing $\mathrm{Pd}$, thus supporting the idea that Pd can induce changes in the grain boundary structure.

The grain growth and the variations in grain boundary character distribution could be produced by the grain boundary complexion transition induced by $\mathrm{Pd}$ as it diffused through SiC. It has been previously reported that nanolayer complexions can have a diffusivity of even two orders of magnitude higher than clean, mono and bilayer complexions and that grain boundary complexion transitions towards more disordered structures can induce grain growth. ${ }^{15}$ This grain boundary complexion transition could explain the grain growth induced by Pd and irradiation previously reported by O'Connell et al. ${ }^{7,} 16$ Therefore, our results suggest that as Pd diffuses through the grain boundary, it can interact with $\mathrm{SiC}$ leading to a higher degree of disorder at the grain boundary. This has important implications since Pd might be able to indirectly affect the diffusion of other elements, not necessarily by forming solid solutions as previously suggested, but by rapidly diffusing through $\mathrm{SiC}$ while 
leaving paths for faster diffusion. This result is supported by previous modeling work that shows that even a single $\mathrm{Pd}$ atom could induce distortions at the grain boundary. ${ }^{17}$

Overall, it should be stressed that although it is expected that secondary elements such as Pd can play a role in fission product transport, current results suggest that the presence of secondary elements alone (like $\mathrm{Pd}$ ) cannot fully explain the enhanced diffusion of elements such as Ag in TRISO fuel particles. It has been observed that $\mathrm{Pd}$ can be found in coated particles with either high or low retention of fission products, ${ }^{16}, 18$ and that despite having a mixture of $\mathrm{Pd} / \mathrm{Ag}$ in contact with $\mathrm{SiC}$, only the irradiated sample exhibited higher diffusion rates of these elements. This suggests that it is the combination of irradiation, temperature, secondary elements and chemical potential that will control the energy and transformation of the characteristics of the grain boundaries ${ }^{19,20}$ (grain boundary complexions and complexions transitions) and dictate the diffusivities observed at high temperatures

\section{Conclusions}

In this work we observed that $\mathrm{Pd}$ can affect the chemical composition of $\mathrm{SiC}$ as it diffuses through SiC by leaving areas with a higher concentration of carbon, thus inducing grain growth and the increase of the concentration of high angle grain boundaries. This suggests that $\mathrm{Pd}$ can induce a grain boundary complexion transition by forming an amorphous nanolayer. This work suggests a new way in which Pd can enhance the diffusion of other fission products in TRISO fuel particles. 


\section{Acknowledgments}

Authors would like to acknowledge CONACYT for the Ph.D. grants awarded to F. Cancino-Trejo and D. Navarro-Solis. Finally, the authors would like to thank Dow Chemicals for providing the SiC wafers.

\section{References}

1. Petti DA, Buongiorno J, Maki JT, et al. Key differences in the fabrication, irradiation and high temperature accident testing of US and German TRISOcoated particle fuel, and their implications on fuel performance. Nucl Eng Des 2003;222:281-297.

2. Minato K, Ogawa T, Fukuda K, et al. Fission product behavior in Trisocoated UO2 fuel particles. J Nucl Mater 1994;208:266-281.

3. Mehner A-W, Heit W, Röllig K, et al. Spherical fuel elements for advanced HTR manufacture and qualification by irradiation testing. J Nucl Mater $1990 ; 171: 9-18$.

4. Minato K, Ogawa T, Kashimura S, et al. Fission product palladium-silicon carbide interaction in HTGR fuel particles. J Nucl Mater 1990;172:184-196.

5. López-Honorato E, Fu K, Meadows PJ, et al. Effect of microstructure on the resilience of silicon carbide to palladium attack. J Am Ceram Soc 2010;93:4135-4141.

6. Gentile M, Xiao P, Abram T. Palladium interaction with silicon carbide. J Nucl Mater 2015;462:100-107. 
7. Neethling J, O'Connell J, Olivier E. Palladium assisted silver transport in polycrystalline SiC. Nucl Eng Des 2012;251:230-234.

8. Van Rooyen I, Lillo T, Wu Y. Identification of silver and palladium in irradiated TRISO coated particles of the AGR-1 experiment. J Nucl Mater 2014;446:178-186.

9. Lillo T, Van Rooyen I. Associations of Pd, $\mathrm{U}$ and $\mathrm{Ag}$ in the SiC layer of neutron-irradiated TRISO fuel. J Nucl Mater 2015;460:97-106.

10. López-Honorato E, Yang D, Tan J, et al. Silver diffusion in coated fuel particles. J Am Ceram Soc 2010;93:3076-3079.

11. Dillon SJ, Harmer MP, Luo J. Grain boundary complexions in ceramics and metals: an overview. Jom 2009;61:38-44.

12. Cancino-Trejo F, Navarro-Solis DJ, López-Honorato E, et al. Grain boundary complexions in silicon carbide. J Am Ceram Soc 2018;101:10091013.

13. Gerczak TJ, Hunn JD, Lowden RA, et al. SiC layer microstructure in AGR-1 and AGR-2 TRISO fuel particles and the influence of its variation on the effective diffusion of key fission products. J Nucl Mater 2016;480:257-270.

14. Pearson $\mathrm{RL}$, Lauf $\mathrm{R}$, Lindemer $\mathrm{T}$. Interaction of palladium, the rare earth, and silver with silicon carbide in HTGR fuel particles. In: Oak Ridge National Lab., TN (USA); 1982.

15. Dillon SJ, Tang M, Carter WC, et al. Complexion: a new concept for kinetic engineering in materials science. Acta Mater 2007;55:6208-6218.

16. O'connell J, Neethling J. Ag transport in high temperature neutron irradiated 3C-SiC. J Nucl Mater 2014;445:20-25. 
17. Rabone J, López-Honorato E. Density functional theory metadynamics of silver, caesium and palladium diffusion at $\beta$-sic grain boundaries. $J \mathrm{Nucl}$ Mater 2015;458:56-63.

18. O'Connell JH, Neethling JH. Palladium and ruthenium supported silver migration in 3C-silicon carbide. J Nucl Mater 2015;456:436-441.

19. Bojarski SA, Knighting J, Ma SL, et al. The relationship between grain boundary energy, grain boundary complexion transitions, and grain size in Ca-doped yttria. In: Mater Sci Forum: Trans Tech Publ; 2013. pp. 87-92.

20. Frolov T, Divinski S, Asta M, et al. Effect of interface phase transformations on diffusion and segregation in high-angle grain boundaries. Phys Rev Lett $2013 ; 110: 255502$. 


\section{List of Figure Captions}

Figure 1. (a) Presence of Pd within SiC and (b) inverse pole figure (IPF) and the standard stereographic triangle (SST).

Figure 2. Grain boundary character distribution (GBCD) of $\mathrm{SiC}$ before and after heat treatment with $\mathrm{Pd}$.

Figure 3. (a) HRTEM image of a particle of palladium in a SiC grain boundary; (b) combined Pd and C EDS map; (c) carbon EDS map y (d) silicon EDS map. In (d) is possible to observe a Si deficiency (indicated by the white bars), whereas in (c) is possible to identify the presence of excess carbon. 


\section{List of Figures}

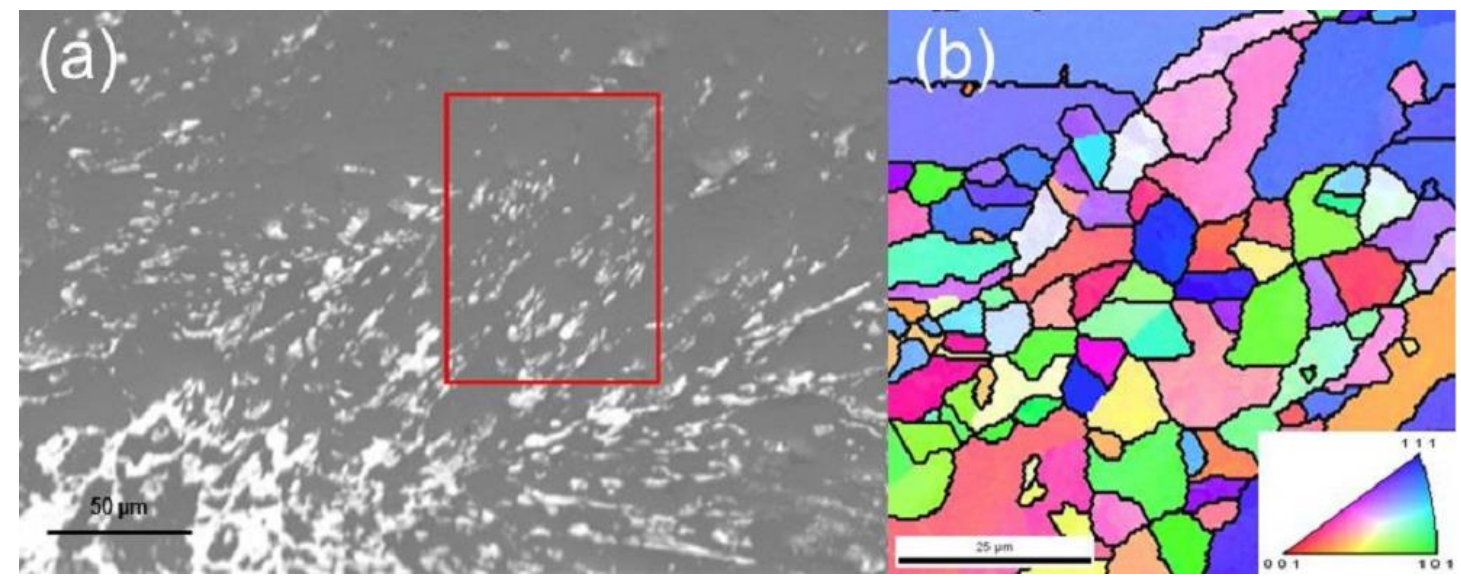

Figure 1. (a) Presence of $\mathrm{Pd}$ within $\mathrm{SiC}$ and (b) inverse pole figure (IPF) and the standard stereographic triangle (SST).

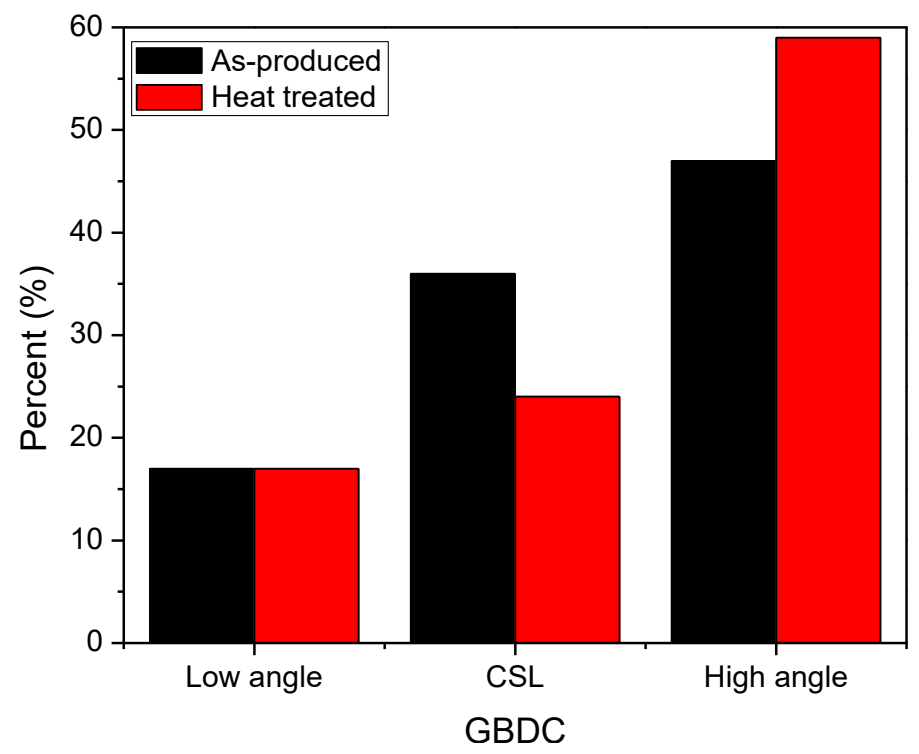

Figure 2. Grain boundary character distribution (GBCD) of SiC before and after heat treatment with $\mathrm{Pd}$. 


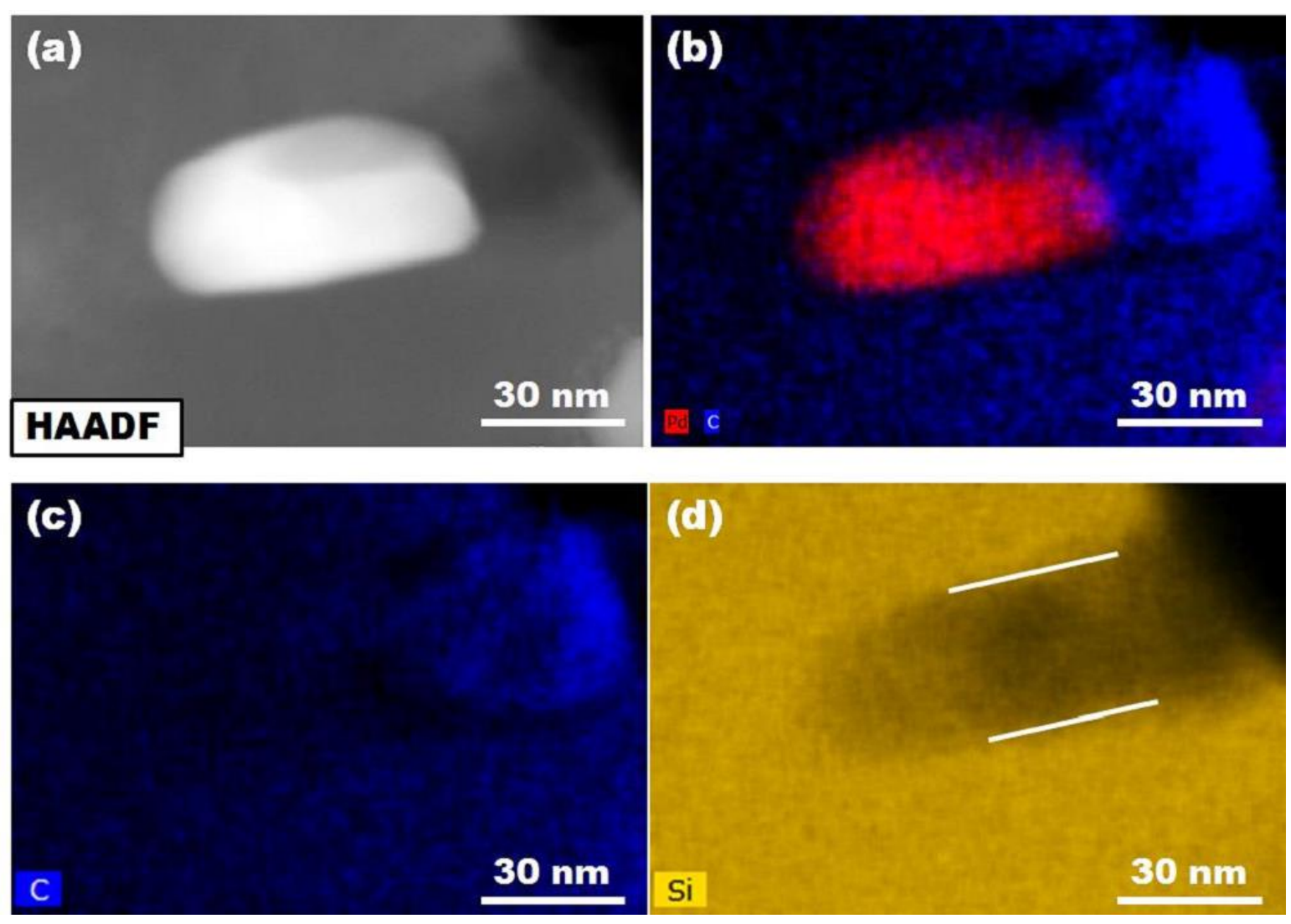

Figure 3. (a) HRTEM image of a particle of palladium in a SiC grain boundary; (b) combined Pd and C EDS map; (c) carbon EDS map y (d) silicon EDS map. In (d) is possible to observe a Si deficiency (indicated by the white bars), whereas in (c) is possible to identify the presence of excess carbon. 


\section{Supplemental Material}

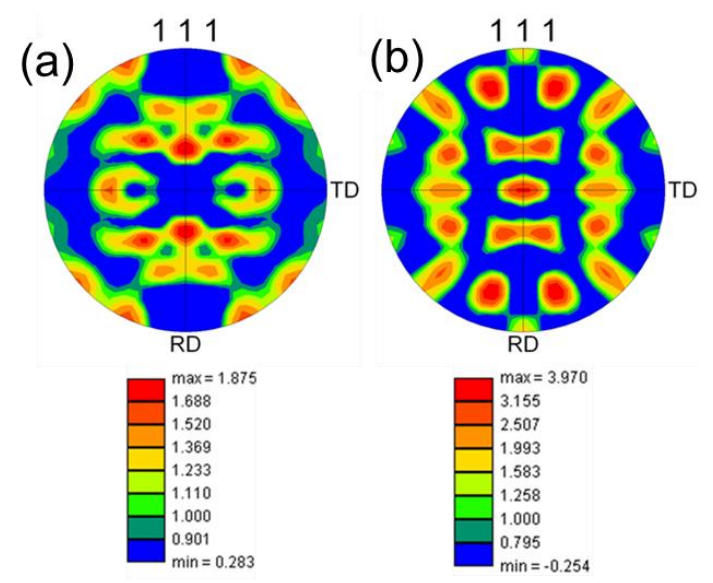

Figure S1. Pole figures of (a) as-produced $\mathrm{SiC}$ and (b) $\mathrm{SiC}$ heat treated with $\mathrm{Pd}$ at $1300^{\circ} \mathrm{C}$. 


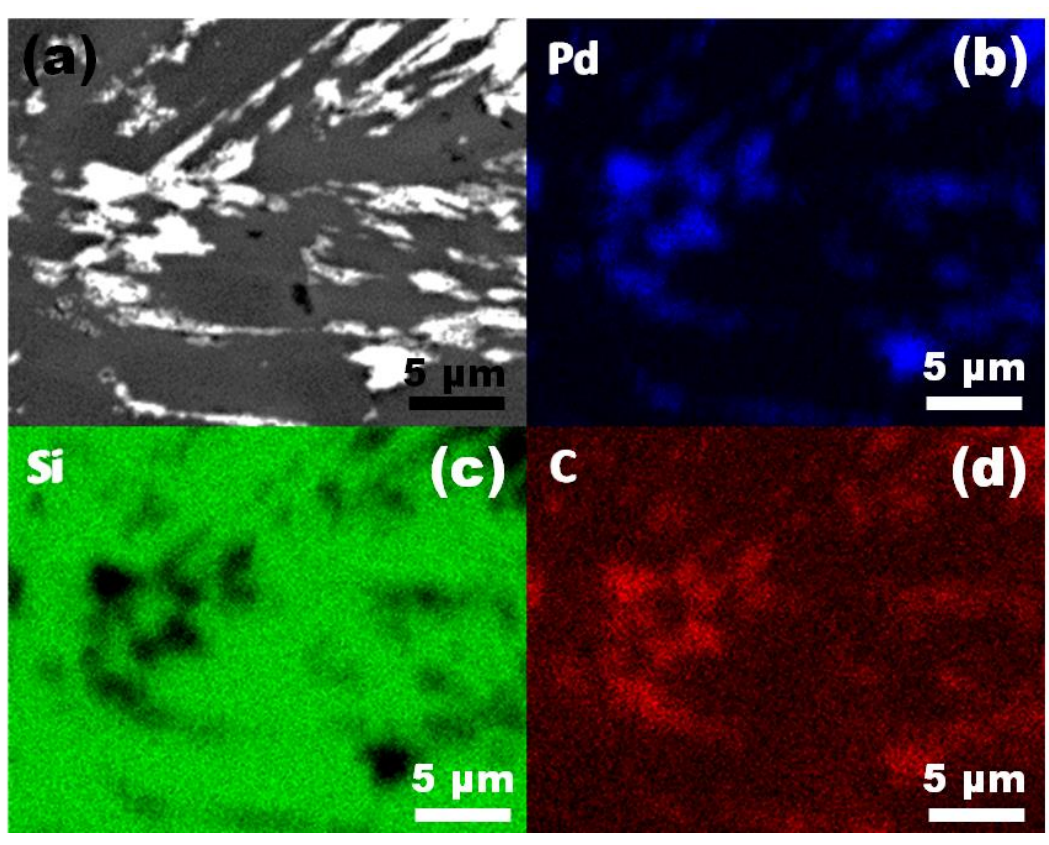

Figure S2. Element maps of an area with a high concentration of Pd in the polycrystalline monolith of $\mathrm{SiC}$. (a) micrograph of $\mathrm{Pd}$; (b) element map of $\mathrm{Pd}$; (c) element map of $\mathrm{Si}$; (d) element map of $\mathrm{C}$.

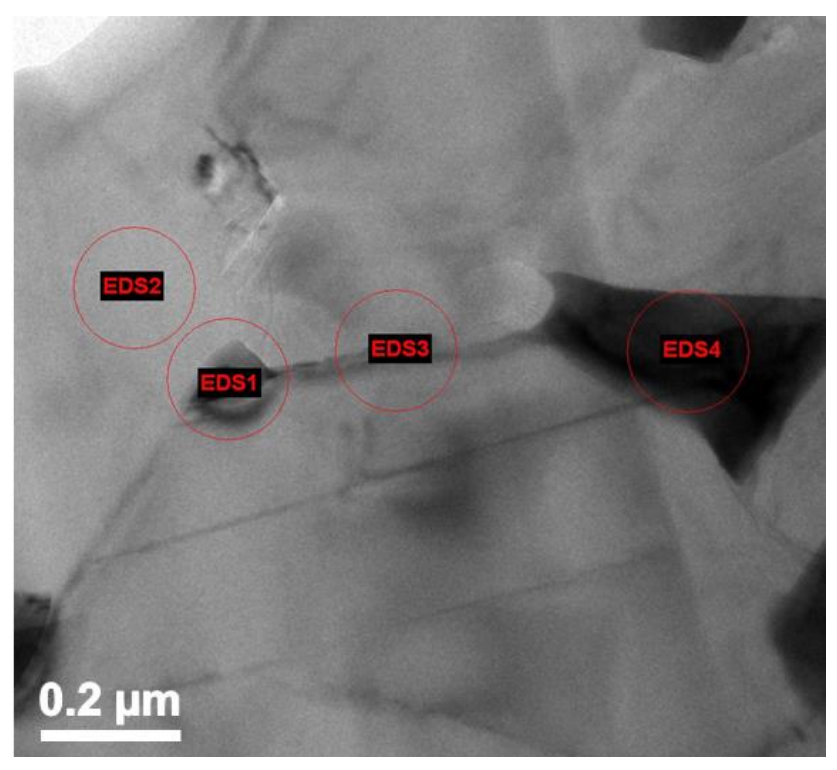

Figure S3. TEM micrograph showing the presence of two regions with $\mathrm{Pd}$ and the formation of a nanolayer. 
Table S1. EDS element análisis of the regions described in Figure S2.

\begin{tabular}{cccc}
\hline EDS & \% Atomic (C) & \% Atomic (Si) & \% Atomic (Pd) \\
\hline $\mathbf{1}$ & 80.71 & 18.31 & 0.92 \\
$\mathbf{2}$ & 77.89 & 22.08 & 0.01 \\
$\mathbf{3}$ & 85.61 & 14.38 & 0.00 \\
$\mathbf{4}$ & 69.11 & 26.37 & 4.43 \\
\hline
\end{tabular}

